\title{
Regional maps of rate of change of pollen percentage as a tool for climate change visualization
}

\author{
Adam WALANUS ${ }^{1, *}$ and Dorota NALEPKA ${ }^{2}$ \\ 1 AGH University of Science and Technology, Al. A. Mickiewicza 30, 30-059 Kraków, Poland \\ 2 W. Szafer Institute of Botany, Polish Academy of Sciences, Lubicz 46, 31-512 Kraków, Poland
}

Walanus A. and Nalepka D. (2013) Regional maps of rate of change of pollen percentage as a tool for climate change visualization. Geological Quarterly, 57 (2): 353-356, doi: 10.7306/gq.1098

\begin{abstract}
Isoline maps of percentage of pollen, obtained for different time horizons through the Holocene, are a typical tool for palaeobotanical studies. In connection with the West Carpathian project the authors have developed the idea of graphically presenting on the map a rate of change of the pollen percentage. Such a map is based on the data from two time horizons. The precision of such a type of map, which shows the \%/change/100 yrs, and in which the value can be negative as well as positive, is lower that of a typical isopollen map. However, this type of map gives a direct insight into changes in the plant cover, which are related to climate change.
\end{abstract}

Key words: isopollen maps, rate-of-change map.

\section{INTRODUCTION}

Palaeobotany, especially palynology, serves as a palaeoclimate proxy data source, since the taxonomic assemblages indicate many weather parameters with relative accuracy, such as average or extreme temperatures or precipitation. Regional isopollen maps (Szafer, 1935), produced for time horizons from the Holocene and Late Glacial (e.g., RalskaJasiewiczowa et al., 2004), are an almost unique source of geographical insight into the plant cover of the past. Since palynological data consists, as a rule, of full profiles frequently covering a geological epoch, it is typical to have isopollen maps not only for one time horizon (Huntley and Birks, 1983; Hoek, $1997 a, b)$, but also for a series of horizons. It is therefore natural to analyse not only one given map, but two neighbouring maps, in search of some pattern of change of plant cover.

The primary result of such an analysis is information regarding in which areas the amount of pollen percentage of a given taxon rises or falls. The question how well the pollen percentage does in fact represent the vegetation is another matter. That problem will not be discussed here, since many papers considering the subject of isopollen maps have already covered this (e.g., Szafer, 1935; Huntley and Birks, 1983; RalskaJasiewiczowa et al., 2004), as have more recent publications (Gaillard et al., 2008).

\footnotetext{
* Corresponding author: walanus@geol.agh.edu.pl
}

Received: October 1, 2012; accepted: January 3, 2013; first published online: May 21, 2013

\section{THE IDEA OF THE RATE OF CHANGE MAPS}

For each selected point on the map, it is simple to calculate the difference in pollen percentage. Let us denote is difference as $\Delta P$ (the older $P$ is subtracted from the younger value). The time span $\Delta T$ for the two given maps would be of the order of hundreds of years up to 1000 years. The ratio $R=\Delta P / \Delta T$ is simply the rate of change of pollen percentage for a given geographical position.

Pollen percentage values are plotted on the maps, as a rule, making use of the isoline idea, which makes the map more readable. The natural, continuous values of the estimated pollen percentage are categorised into a set of bands; for example $0-0.1 \%$, $0.1-0.2 \%, 0.2-0.5 \%$, and so on. It is clear that the $R$ (rate of change) should be calculated prior to this categorization. The map of $R$ values runs the same way as do the $P$-maps and they will also finally be categorised by isolines. The only significant difference, however, is that twice the volume of data is necessary here; namely the $P$ values, for all the sites available, for two time horizons. A necessary, additional data item is the $\Delta T$. This seems to be trivial, being simply $\Delta T=500$ years, for example; in practice, though, the question of the precision of $\Delta T$ is far from simple.

\section{THE MAP CONSTRUCTION}

The palynological profiles are radiocarbon dated as well as dated by comparison with other, neighbouring profiles. The second method does not necessarily make the argument circular, since the data are multivariate. Correlation by one taxon imposes the same correlation for all other taxa. However, even the most precise elements of the dating process, namely the radiocarbon dates, are not free of uncertainty. The only solid fact is that the ${ }^{14} \mathrm{C}$ ages have a well defined confidence band (as long as there is no gross error, for example of the type of sam- 

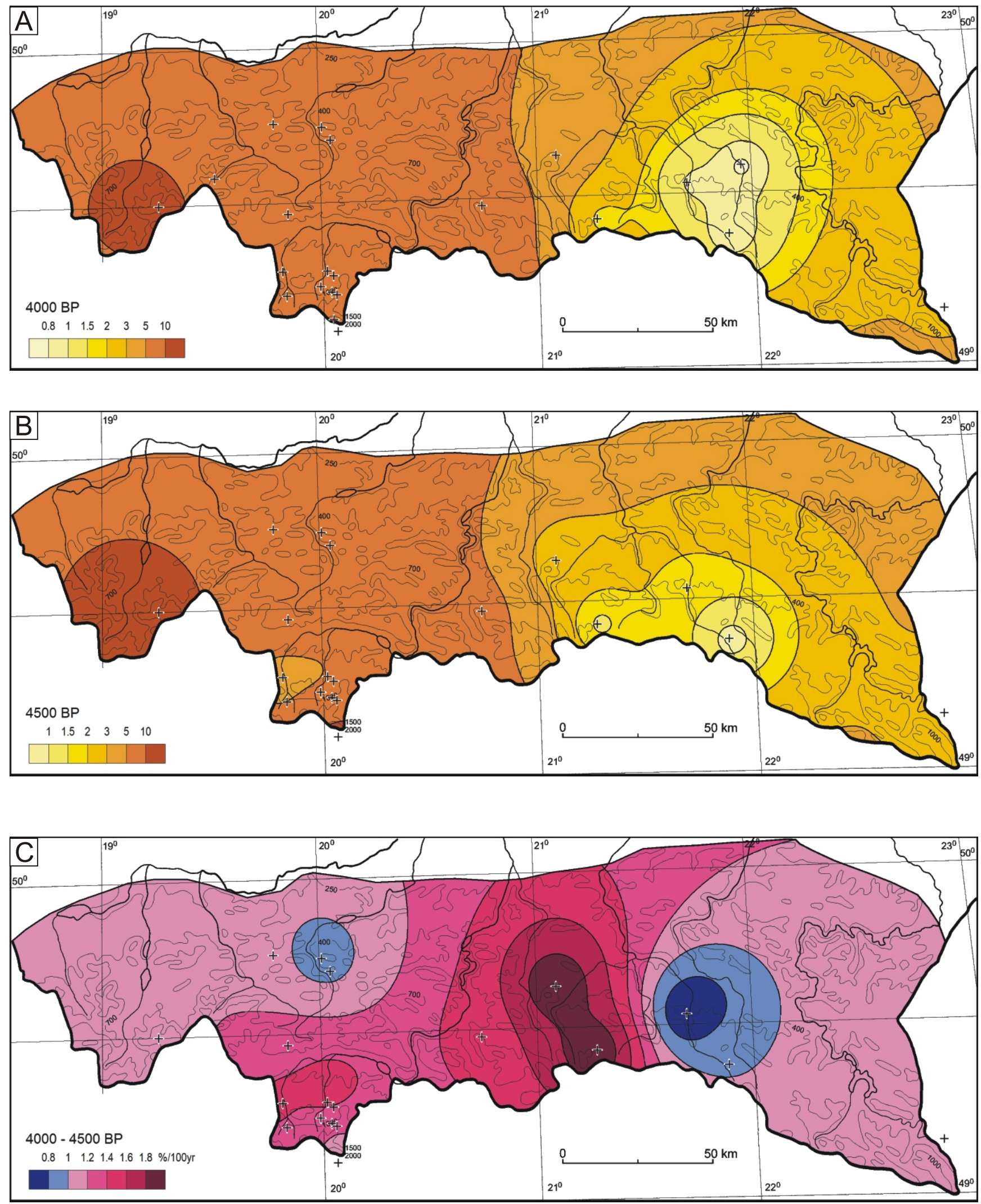

Fig. 1. Two typical isopollen maps (A, B) of the percentage of an example taxon, obtained for time horizons $4000{ }^{14} \mathrm{C}$ BP (A), and $4500{ }^{14} \mathrm{C}$ BP (B); the third map (C) comprises the information from both the above time horizons showing differences in percentages recalculated to the time unit (100 yrs)

The value range of $(A)$, and $(B)$ is roughly from 1 to $10 \%$, while for $(C)$ it is from -0.4 to $+1.0 \% / 100 \mathrm{yrs}$ 

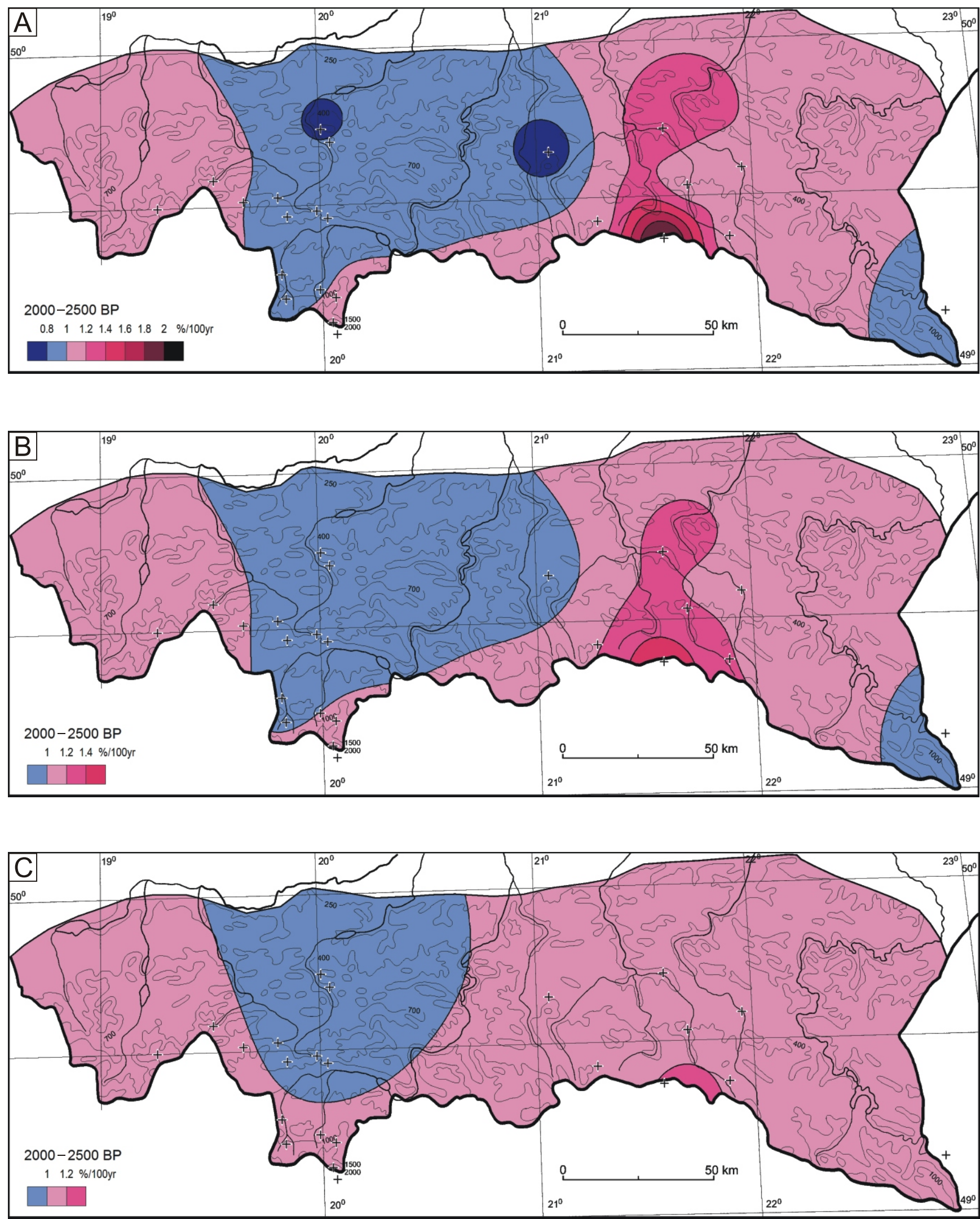

Fig. 2. The examples of different data presentation accuracy

The median (B) map is probably a good trade-off between the loss of valuable information and artificially creating information 
ple/context). Radiocarbon dates are rare, at least for older profiles, so relative dating is necessary. Finally, interpolation by the subjectively chosen method creates an additional source of uncertainty in terms of unknown statistical features. To produce a map for each profile requires its samples to be dated. It is relatively easy to attach a number of years to the samples, but it is almost impossible to estimate the precision of the dating. Also, this is not the final step. While the map is defined to illustrate the time $T$ (for example $T=4500 \mathrm{yr}$ b2k; Fig. 1B), it is not reasonable to expect to have samples in the profiles of that age label. A further interpolation is necessary. However, taking into account the low time resolution of dating, a Gaussian smoothing of samples from the vicinity of $T$ is applied, instead of a simple (linear) interpolation. The Gaussian weights are defined by the normal distribution bell curve of the mean value equal to $T$ and $\sigma$ equal to, for example, 200 years. It means that samples of age $T \pm 1 \sigma$ are of $61 \%$ (not $68 \%$ ) importance in terms of the $T$ age, and that of age $T \pm 2 \sigma$ are of $14 \%$ weight, while at $T \pm 3 \sigma$ we approach $1 \%$, which is practically zero. However, $3 \sigma$ means 600 years (in fact \pm 600 years), if $\sigma$ is assumed to be equal to 200 years.

The last interpolation is that between sites, in the geographical sense. The final result is the $P$ percentage for each map point. The value of rate of change is calculated as the difference of $P$ 's from two maps divided by $\Delta T$. If there are $N P$-maps ( $N$ time horizons), then the total number of $\mathrm{R}$-maps will be $\mathrm{N}-1$. The $R$-map calculated based on the $P$-maps for time $T$ and $T-\Delta T$ should be interpreted as illustrating the time $T-\Delta T / 2$ (Fig. 1C).

From the numerical point of view of computer calculations, it is possible to split up the Holocene into 1 year sections. One can produce over 10,000 maps and even publish them (on the web). This is similar to a movie based on the maps, which require thousands of frames. The map obtained for $T=1234 \mathrm{yr}$ b2k may be reliable enough if calculated with $\sigma$ no less than, say 100 years. Of course, this does not mean that such a map illustrates precisely that time point. Calculation of $R$-maps with a too small $\Delta T$ is unreasonable. If the two quantities $\Delta T$ and $\sigma$ are interrelated, the relationship would be as simple as $\sigma=\Delta T / 2$; however, it would be sensible to also use another factor.

\section{ADVANTAGE OF THE RATE OF CHANGE MAPS OVER THE CONVENTIONAL ISOPOLLEN MAPS}

It is clear from the maps in Figure $1 A$ and $B$ that the given taxon is more abundant in the west than the east. However, only a map charting the rate of change makes clear more subtle features connected with the evolution of the taxon cover. In the middle of the given area, there is an evident increase of pollen. That feature can be discovered when inspecting both the (Fig. 1A) and (Fig. 1B) maps in parallel. Similarly, the fall in pollen percentage visible on (Fig. 1C) on the right can be recognized from (Fig. 1A) and (Fig. 1B); however, on (Fig. 1C), it is simply and directly indicated, with its numerical value (between -0.4 and $-0.2 \% / 100 \mathrm{yrs}$ ).

Selection of the value of $\Delta T$ is a trade-off between the high number of maps obtained for the given database, and of that particular map accuracy (reliability). The second value is very different since it is measured (while the first one is simply a number). On Figure 2 are shown maps with different smoothing (averaging) degrees. The extremes would be: the representation of each site included with its own value; or, on the other hand, one value used right across the map. Such extremes are not presented below. However, the map (Fig. 2A) is probably slightly too precise, in terms of the reliability of the visible features. Map (Fig. 2C), however, seems to be too poor in terms of sufficient detail. The intermediate one (Fig. 2B) is probably a good option.

Appreciation of the quality offered by maps is possible with the application of the bootstrapping method (Walanus and Nalepka, 2009), or by visual inspection of a series of maps by an experienced scientist. The proposed maps of rate of change of the percentage pollen (Fig. 2) are very sensitive to overestimation in terms of the amount of information they convey. This is connected with the fact that twice as much data has been used in their creation than for typical isopollen maps. However, the potential map reader has to bear in mind that in the case of differentiation, data imprecision grows, because it is in summary form, while the data values themselves may easily be close to zero after subtraction. If used with a due amount of care, the rate-of-change maps could be seen, however, as a good tool for determining plant cover change indicators.

Acknowledgments. The study reported in this article was partly financed by the Statutory Research Task of AGH University of Science and Technology, Faculty of Geology, Geophysics and Environmental Protection, partly by the Statutory Research of W. Szafer Institute of Botany PAS, and partly by research project No. N N304 293937 "Holocene history of vegetation in West Carpathians based on isopollen maps" with contributions by: W. Granoszewski, P. Kołaczek, J. Madeja, Z. Mirek, D. Nalepka, A. Obidowicz (head), K. Szczepanek, A. Wacnik, and A. Walanus. The authors would like to thank Prof. K. Milecka and an anonymous reviewer for valuable suggestions.

\section{REFERENCES}

Gaillard M.-J., Sugita S., Bunting M.J., Middleton R., Broström A., Caseldine Ch., Giesecke Th., Hellman S.E.V., Hicks Sh., Hjelle K., Langdon C., Nielsen A.-B., Poska A., von Stedingk H., Veski S. and POLLANDCAL members (2008) The use of modelling and simulation approach in reconstructing past landscapes from fossil pollen data: a review and results from the POLLANDCAL network. Vegetation History and Archaeobotany, 17 (5): 419-443.

Hoek W.Z. (1997a) Palaeogeography of Lateglacial vegetations. Aspects of Lateglacial and Early Holocene vegetation, abiotic landscape, and climate in the Netherlands. Thesis, Vrije Universiteit, Amsterdam.

Hoek W.Z. (1997b) Atlas to Palaeogeography of Lateglacial Vegetations; Maps of Lateglacial and Early Holocene landscape and vegetation in the Netherlands, with an extensive review of available palynological data. Vrije Universiteit, Amsterdam.
Huntley B., Birks H.J.B. (1983) An Atlas of Past and Present Pollen Maps for Europe: 0-13,000 Years Ago. Cambridge University Press.

Ralska-Jasiewiczowa M., Latałowa M., Wasylikowa K., Tobolski K., Madeyska E., Wright H. E. Jr., Turner Ch., eds. (2004) Late Glacial and Holocene history of vegetation in Poland based on isopollen maps. W. Szafer Institute of Botany, Polish Academy of Sciences. Kraków.

Szafer W. (1935) The significance of isopollen lines for the investigation of the geographic distribution of trees in the Post- Glacial period. Bulletin de l'Academie Polonaise des Sciences, B: 235-239.

Walanus A., Nalepka D. (2009) Statistical confidence on Maps by Bootstrapping. Geospatial Crossroads @ GI Formu 09. Proceedings of the Geoinformatics Forum Salzburg. Car/Griesebner/Strobl (Eds.): 228-231. Wichmann. 